the best way to count the number of cases. Some overuse of the term sudden infant death syndrome has long been recognised, and a recent study has suggested that this is considerable. ${ }^{+}$Our findings must therefore be assessed with this in mind. Nevertheless, there is no evidence to suggest that there might be more false positive cases of sudden infant death syndrome in either of the age groups considered by us.

Most studies of sudden infant death syndrome suffer from a lack of detailed case definition. Also many studies are based on small numbers and often show no variation by day of the week. Occasionally, days other than the weekend have shown an excess. ${ }^{2}$ One powerful study using data from infant death certificates in England and Wales during 1969-79 found that deaths attributed to congenital malformations and "sudden deaths" (including sudden infant death syndrome) were significantly more common at weekends but that other causes were not. Furthermore, the effect was sufficiently strong to be evident in deaths from all causes as well. ${ }^{5}$ The recent multicentre study of 988 postperinatal deaths showed no daily excess for all causes but did not report the distribution of true cases of sudden infant death syndrome. ${ }^{+}$

The greater number of deaths at weekends may be a genuine phenomenon, perhaps reflecting changed parental routines, hesitation or diffidence in calling the doctor for apparently minor illness, or deficiencies in primary care. It is possible that parents, and perhaps doctors, take more chances in this way with older infants. This interpretation of our results is compatible with the conclusions of the Knowelden report ${ }^{4}$ and the suggestion that some of the deaths labelled sudden infant death syndrome are preventable.

We thank Christina Perry, Department of Community Medicine and Medical Statistics, University of Southampton, for typing the manuscript.

1 Peterson DR. Evolution of the epidemiology of sudden infant death syndrome. Epidemiol Rev 1980;2:97-112

2 Golding J, Limerick S, Macfarlane JA. Sudden infant deaths: patterns, puzzles and problems. Shepton Mallett: Open Books Publishing Ltd, 1985.

3 Office of Population Censuses and Surveys and London School of Hygiene and Tropical Medicine. Studies in sudden infant deaths. London: HMSO, 1982. (Studies on Medical and Population Subjects, No 45.

4 Knowelden J, Keeling J, Nicholl J. A multicentre study of post-neonatal mortality. London: DHSS, 1984

5 Macfarlane AJ, Gardner A. Day of the week variation in postneonatal mortalitv. London: HMSO 1982. (Studies on Medical and Population Subjects, No 45.)

Accepted 16 May 1986

Medical Statistics Division, Office of Population Censuses and Surveys St Catherine's House, London WC2B 6JP, and Department of Community Medicine and Medical Statistics, University of Southampton, Southampton SO9 4XY

M F G MURPHY, MB, BCHIR, medical statistician and lecturer in clinical epidemiology

Department of Community Medicine and Medical Statistics, University of Southampton, Southampton SO9 4XY

$M \mathrm{~J}$ CAMPBELL, BA, PHD, lecturer in medical statistics

Department of Clinical Epidemiology and Social Medicine, St George's Hospital Medical School, London SW17 0RE

D R JONES, PHD, senior lecturer in epidemiology

Correspondence to: Dr Murphy.

\section{Use of a visual analogue scale in the diagnosis of urinary incontinence}

We have assessed the value of a visual analogue scale in the diagnosis of urinary incontinence in women.

\section{Patients, methods, and results}

Thirty five consecutive women attending a urodynamic clinic for investigation of urinary incontinence were asked, as part of their assessment, to indicate the severity of their urinary symptoms by marking a $10 \mathrm{~cm}$ analogue scale. This was done before a history was taken and before urodynamic studies were performed. The mark was measured to the nearest millimetre and scored from $0-100$.

After the scale had been marked a filling and provocation cystometrogram was performed using a three channel subtraction recorder to measure true detrusor pressure. In this way a urodynamic diagnosis was made. The terms used conform with definitions of the International Continence Society.

Results were as follows: 16 patients had detrusor instability, 14 had genuine stress incontinence, and two had both. In three patients results were normal.
The mean (SD) analogue score was $62.06 \mathrm{~mm}(12.32)$ in the patients with detrusor instability and $26.28 \mathrm{~mm}(10.91)$ in those with stress incontinence. The difference between the mean scores for the two groups was highly significant $(\mathrm{p}<0.001)$, as assessed by Student's $t$ test. There was minimal overlap of the two groups, with only three women with detrusor instability having scores lower than the highest score in the group with stress incontinence (figure). The two groups were well matched for age, parity, and duration of symptoms.

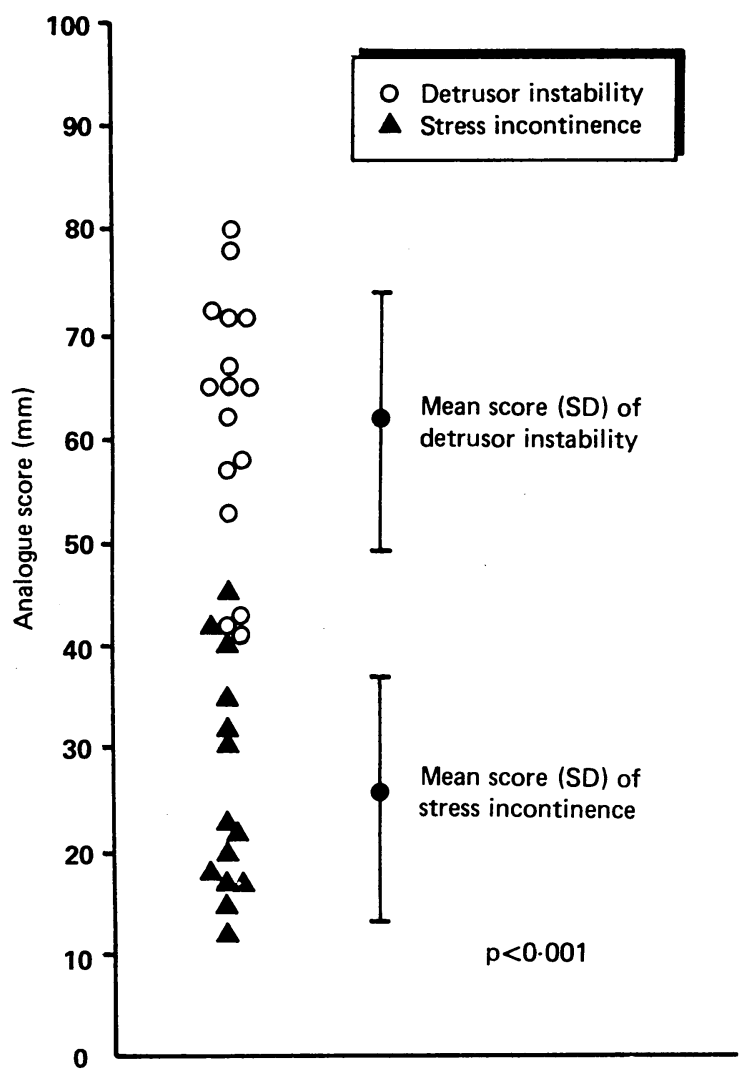

Analogue scores in women with genuine stress: incontinence or detrusor instability.

The two patients with both detrusor instability and stress incontinence had scores of $69 \mathrm{~mm}$ and $74 \mathrm{~mm}$, and for women with normal results scores were 16 $\mathrm{mm}, 23 \mathrm{~mm}$, and $26 \mathrm{~mm}$.

\section{Comment}

Clinical investigation of the cause of urinary incontinence is often inaccurate ${ }^{1}$ and urodynamic studies are essential if the correct diagnosis is to be made. The choice of treatment, either surgical or medical, depends on a correct diagnosis. Operations are often unsuccessful in unsuspected detrusor instability. ${ }^{2}$

Analogue scales are well established for subjective measurement of pain, ${ }^{3}$ but they have not been used before to assess urinary symptoms. Our results showed a significant difference between the analogue scores of the two groups. More importantly, there was little overlap between the two groups.

Although a diagnosis can be confirmed only by urodynamic studies, when these investigations are not available an analogue score could be used as a screening test before surgical treatment of incontinence, as this seems to be more accurate than clinical assessment alone. In patients with scores above 40 surgical treatment should be deferred until urodynamic studies can be arranged. This may save patients from unnecessary and inappropriate operations. As analogue scores are non-invasive they also avoid the $2 \%$ risk of urinary tract infection caused by urodynamic studies. ${ }^{4}$

Women with detrusor instability appear to have a worse perception of their symptoms than women with stress incontinence. This might be because the symptoms of urgency, urge incontinence, and nocturia are worse than that of stress incontinence. Alternatively, it might be because the psychological profile of women with detrusor instability is different from that of women with genuine stress incontinence. This is supported by the success of psychomedical treatment of detrusor instability. ${ }^{5}$

A controlled trial comparing urodynamic studies with the analogue score is needed to assess the clinical value of this method in places where urodynamic studies are not readily available. 
This work was funded by a grant from the research support group of the Greater Glasgow Health Board.

1 Jarvis G, Hall S, Stamp S, Millar D, Johnson A. An assessment of urodynamic examination in incontinent women. Br $\mathcal{F}$ Obstet Gynaecol 1980;87:893-6.

2 Bates CP, Loose H, Stanton SL. The objective study of incontinence after repair operations. Surg Gynecol Obstet 1973;136:17-22.

3 Huskisson EC. Measurement of Pain. Lancet 1974;ii:1127-31.

4 Walter S, Vejlsgaard R. Diagnostic catheterisation and bacteruria in women with urinary incontinence. Br f Urol 1978;50:106-8.

5 Frewen WK. An objective assessment of the unstable bladder of psychosomatic origin. $\mathrm{Br} \mathcal{J}$ Urol 1978;50:246-9.

(Accepted 9 May 1986)

Department of Gynaecology, Stobhill General Hospital, Glasgow

D E PARKIN, MB, MRCOG, research registrar

J A DAVIS, MB, MRCOG, consultant gynaecologist

Correspondence to: Dr D E Parkin.

\section{A case of scurvy}

Sporadic cases of scurvy may continue to occur despite improved standards of living and food supply. Those at risk include people living alone and those with peculiar dietary habits, which are often taken to relieve symptoms. We report a case of scurvy in a young man whose diet was severely deficient in vitamin $\mathrm{C}$ as a result of exclusions devised to prevent alleged hypersensitivity to food. Current lay enthusiasm for dietary treatment of a great variety of symptoms may well lead to an increase in this type of deficiency. ${ }^{12}$

\section{Case report}

A 28 year old man, educationally below average, presented as an emergency with malaise, immobility, and a rash. Three years previously he had been referred for investigation of epilepsy, which had been diagnosed 14 years before. His parents, with whom he lived, had become convinced that his fits were due to food allergy, which they also blamed for his intermittent attacks of flatulence. Temporal lobe epilepsy had been diagnosed, and concurrent investigation for coeliac disease (including small intestinal biopsy) yielded negative results.

He was advised to eat normally, but his parents remained determined to prove

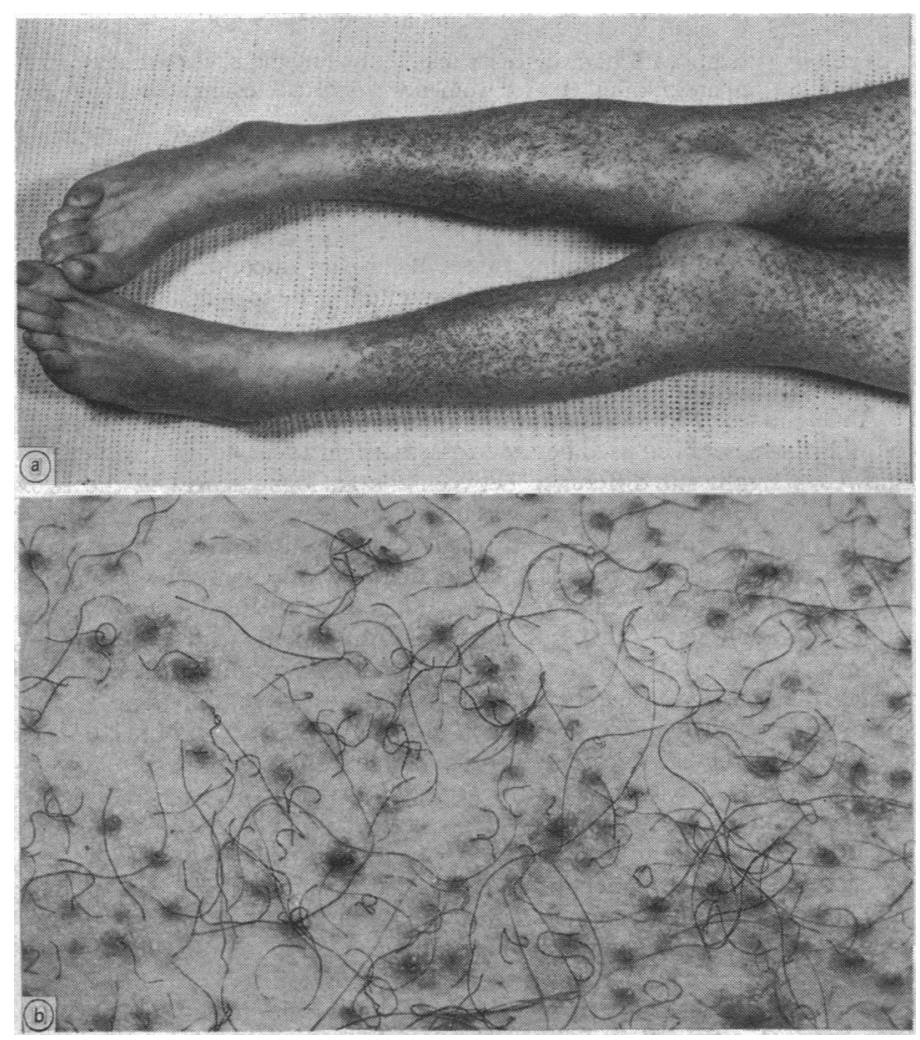

Pronounced petechial rash $(a)$ and corkscrew hairs $(b)$. that he suffered from food allergy. To this end he consulted many practitioners, each of whom added different advice and fresh exclusions to his dwindling diet. A few months before admission he attended an alternative medicine clinic, which excluded all potatoes, oranges, and lemons on the unsupported grounds of allergy. No advice seems to have been given about vitamin intake. His mother was strict with these exclusions, so that on admission his diet consisted of only eight foodstuffs: gluten free bread, rice cakes, vegetable margarine, apple juice, steamed white cod, brown rice, yeast pâté, and occasional portions of green vegetables. His daily intake with this diet was protein $62 \mathrm{~g}$, fat $66 \mathrm{~g}$, and carbohydrate $305 \mathrm{~g}(8 \cdot 8 \mathrm{MJ} ; 2095 \mathrm{kcal})$. His daily intake of vitamin C was $10.2 \mathrm{mg}$ (recommended daily intake $30 \mathrm{mg}^{3}$ ), of iron $13.4 \mathrm{mg}$, and of folate 7.7 $\mu \mathrm{g}$.

He gave a two month history of increasing fatigue, difficulty in walking, pallor, and a rash over his buttocks and legs, which in the days before his admission had become pronounced (figure) with painful swelling of both knees, ankles, and elbows. There had been one episode of haemoptysis but no overt gastrointestina bleeding. On examination he was pale and thin and had a widespread petechial rash over both buttocks and lower abdomen, with tiny corkscrew hairs. Recent bleeding from the gums was visible, and fresh tender bruising was present behind the knees and ankles, indicating bleeding around these joints.

Investigation showed haemoglobin concentration $84 \mathrm{~g} / 1$, white cell count $5 \cdot 1 \times 10^{9} / 1$, mean corpuscular volume $83 \mathrm{fl}$, and serum $B_{12}$ concentration $153 \mathrm{ng} / \mathrm{l}$; leucocyte ascorbic acid concentrations were too low for accurate measurement. Other investigations, including chest $x$ ray examination, yielded normal results. He made a dramatic recovery, being able to walk within 48 hours after receiving oral vitamin $\mathrm{C}$. He subsequently took vitamin supplements and remained well.

\section{Comment}

Adult scurvy commonly presents with fatigue, weight loss, arthralgia, depression, and weakness. ${ }^{4}$ There is a tendency to bleed, with swollen, friable gums, loosening of the teeth, and perifollicular haemorrhages. Other features include associated anaemia and corkscrew hairs. Our patient's die was grossly deficient in vitamin $\mathrm{C}$ because of his parents' conviction that he had a food allergy. There is widespread interest in alternative medicine, in which dietary exclusions may feature. ${ }^{1}$ Our patient shows the harm that may come from this; as scurvy is uncommon, delay in diagnosis may occur. Indeed, patients with scurvy may die suddenly without warning from cardiac failure. ${ }^{5}$ Doctors therefore need to have a heightened index of suspicion for deficiencies when patients are following exclusion diets, for whatever reason.

1 May CD. Food sensitivity: facts and fallacies. Nutr Rev 1984;42:72-8.

2 Royal College of Physicians and British Nutrition Foundation. Food intolerance and food aversion. $f R$ Coll Physicians (Lond) 1984;18:83-123.

3 Committee on Medical Aspects of Food Policy. Recommended daily amounts of food, energy, and nutrients for groups of people in the UK. London: HMSO, 1979.

4 Reuler JB, Broudy VC, Cooney TG. Adult scurvy. JAMA 1985;253:805-7.

5 Sament S. Cardiac disorders in scurvy. N Engl f Med 1970;282:282-3.

(Accepted 19 May 1986)

\section{Queen Alexandra Hospital, Portsmouth}

M HUGHES, MB, BS, house physician

N CLARK, MB, BS, house physician

L FORBES, BSC, SRD, chief dietitian

D G COLIN-JONES, MD, FRCP, consultant physician

Correspondence to: Dr Colin-Jones.

\section{Diabetic renal disease: differences between Asian and white patients}

A recent survey by the World Health Organisation suggested that ethnic differences might result in differences in the prevalence of small vessel disease in diabetics. ${ }^{1}$ We undertook this study to determine whether the prevalence of diabetic nephropathy differed between Asian and white patients attending the Leicester diabetic clinic.

\section{Patients, methods, and results}

We studied 370 consecutive Asian and 368 consecutive white patients who had attended the diabetic clinic for at least one year (table). Patients were regarded as Asian if they originated from the Indian subcontinent (India, Pakistan, Bangladesh, and Sri Lanka). Proteinuria was considered to be present if Albustix testing of urine on at least two occasions at least six weeks apart yielded positive results, 24 hour protein excretion was $>0.5 \mathrm{~g}$, and there was no urinary tract infection or evidence of disease of the renal tract on intravenous pyelography. Retinopathy 